\title{
Lactobacillus plantarum IS-20506 Probiotic Restores Galectin-4 and Myosin-1a Expressions in Duodenum, Jejunum and Ileum of Lipopolysaccharide-induced Rats
}

\author{
Reza Gunadi Ranuh ${ }^{1}$, Alpha Fardah Athiyyah ${ }^{1}$, Andy Darma $^{1}$, Wibi Riawan ${ }^{2}$, \\ Ingrid Suryanti Surono ${ }^{3}$, Ferry Sandra, ${ }^{4, *}$, Subijanto Marto Sudarmo ${ }^{1}$ \\ ${ }^{1}$ Department of Child Health, Dr. Soetomo Hospital, Faculty of Medicine, Universitas Airlangga, Jl. Prof. Dr. Moestopo No. 6-8, Surabaya, Indonesia \\ ${ }^{2}$ Laboratory of Biochemistry and Biomolecular, Universitas Brawijaya, Jl. Veteran, Malang, Indonesia \\ ${ }^{3}$ Food Technology Department, Faculty of Engineering, Bina Nusantara University, Jakarta 11480, Indonesia \\ ${ }^{4}$ Department of Biochemistry and Molecular Biology, Division of Oral Biology, Faculty of Dentistry, Universitas Trisakti, J1. Kyai Tapa No.260, \\ Jakarta, Indonesia \\ ${ }^{*}$ Corresponding author. E-mail: ferry@trisakti.ac.id
}

Received date: Dec 16, 2019; Revised date: Aug 15, 2020; Accepted date: Aug 18, 2020

\section{Abstract}

$\mathrm{B}$ ACKGROUND: Galectin- 4 and Myosin-1a are important proteins for normal intestinal brush border structure and composition. Damage of these proteins by inflammation may alter digestion, absorption and barrier function. Probiotic has been widely known in maintaining gut health. However, the molecular mechanism of Lactobacillus plantarum IS-2056 probiotic in repairing intestinal brush border is not well defined. Therefore, current study was conducted by investigating the Galectin-4 and Myosin-1a expressions in a rodent model.

METHODS: Male Wistar rats were induced with/without lipopolysaccharide (LPS) and treated with/without L. plantarum IS-2056 probiotic. On the seventh day, duodenum, jejunum, and ileum were collected and analyzed with western blot and immunohistochemistry for Galectin-4 and Myosin-1a expressions.
RESULTS: Rats administrated with L. plantarum IS-2056 probiotic showed significant increase of Galectin- 4 and Myosin-1a expressions in duodenum, jejunum, and ileum compared to the control group $(p<0.05)$. While in control group, Galectin-4 level tended to increase in more distal of intestinal segment and Myosin-1a level tended to decrease in more distal intestinal segment.

CONCLUSION: L. plantarum IS-20506 probiotic may facilitate the repairment of damaged intestinal brush border as demonstrated by significant restoration of Galectin- 4 and Myosin-1a expressions in duodenum, jejunum, and ileum of LPS-induced rats.

KEYWORDS: Lactobacillus plantarum, IS-20506, probiotic, galectin-4, myosin-1a, duodenum, jejunum, ileum

Indones Biomed J. 2020; 12(3): 283-7

\section{Introduction}

Intestinal mucosal defense as a cellular unit is comprised by brush border membrane, microvilli core, and epithelial tight junction. There are several proteins play important roles in the defense. Galectin-4 serves as membrane structure of brush border, molecule transport, cell adhesion, and wound healing.(1) Villin, Fimbrin, Myosin-1a,
Myosin-1c, Myosin-1e, and Calmodulin maintain the integrity of microvilli.(2) Occludin and ZO-1 provide important part in maintaining integrity of impermeable tight junction as a complex protein.(3) Together, these provide the first line defense unit called intestinal mucosal barrier.

Intestinal mucosal barrier dysfunction could be caused by immune aberrancy and infection, which are the main pathogenesis of many gastrointestinal diseases. Inflammation induced by pathogenic lipopolysaccharide 
(LPS) will down regulate mucosal barrier proteins, resulting in increasing permeability and susceptibility of bacterial invasion.(4) Tight junction is the main structure connecting intestinal mucosal epithelial cells needed to maintain normal anatomy and physiology of intestinal mucosal barrier.(4)

Probiotics are living bacteria or yeast that could give positive benefits to the host.(5) Lactobacillus plantarum IS-20506 is a one of two L. plantarum strains isolated from dadih, a fermented buffalo milk from Sumatra Island.(6) L. plantarum IS-10506 showed significant role in intestinal stem cells and intestinal mucosal barrier integrity (7), while L. plantarum IS-20506 activity towards mucosal barrier integrity is still unknown. In this study, we investigated the probiotic effect of L. plantarum IS-20506 on intestinal mucosal tight junction protein during intestinal inflammation.

\section{Methods}

\section{Animal Preparation and Treatment}

Fifteen male, weighted 100-120 gram, aged 12 weeks, Wistar rats were procured from central animal facility of Cellular and Molecular Biology Laboratory, Faculty of Science, Universitas Brawijaya, Malang, Indonesia. All rats were given water ad libitum and normal pellet diet containing $20-25 \%$ protein, $5-12 \%$ fat, $2.5 \%$ fiber, and $45-60 \%$ carbohydrate. After 14 days of acclimatization, fifteen rats were equally assigned into 3 groups. The first group was treated with distilled water daily through gavage as control group. The second group was induced with 2.5 $\mathrm{mg} / \mathrm{kg}$ LPS derived from Eschericia coli serotype O55:B5 (Cat. No. L5418, Sigma-Aldrich, St. Louis, MO, USA) through gavage on the first day, then treated with distilled water daily on the following days. The third group was also induced with $2.5 \mathrm{mg} / \mathrm{kg}$ LPS through gavage on the first day, but then treated with $2.5 \mathrm{~mL}$ of $2.67 \times 109 \mathrm{CFU} /$ $\mathrm{mL}$ L. plantarum IS-2056 daily on the following days. Freeze-dried powder of L. plantarum IS-20506 (GenBank accession no. DC860149) was obtained from the Research and Development Laboratory of PT Ultrajaya Milk Industry, Jakarta, Indonesia. Rats were examined and weighted daily. On day 7, rats were sacrificed, then duodenum, jejunum, and ileum were dissected and processed for western blot and immunohistochemistry. This study protocol was approved by Ethical Committee of Faculty of Veterinary Medicine, Universitas Airlangga (No. 028-KE, March 2018).

\section{Western Blot}

Dissected duodenum, jejunum, and ileum were minced and homogenized in a cold lysis buffer. After centrifugation, supernatants were collected as samples. The samples were separated by SDS-polyacrylamide gel electrophoresis and transferred to a polyvinylidene difluoride sheet. After blocking with 5\% skim milk in phosphate-buffered saline, the sheet was incubated with 1:200 goat polyclonal antiGalectin-4 (Q-20) (sc-19289, Santa Cruz Biotechnology, Dallas, TX, USA) or anti-Myosin-1a (C-12) (sc-32698, Santa Cruz Biotechnology) antibody. Secondary antibody was alkaline phosphatase-conjugated donkey anti-goat IgG $(\mathrm{H}+\mathrm{L})$ antibody (SAB3700286, Sigma-Aldrich). The bound antibodies were visualized using 5-bromo-4-chloro3-indolyl phosphate (BCIP)/nitro blue tetrazolium (NBT) substrate system (B1911, Sigma-Aldrich).

\section{Immunohistochemistry}

Dissected duodenum, jejunum, and ileum were fixed and processed for making paraffin blocks. The paraffin blocks were sliced in $4 \mu \mathrm{m}$, de-paraffinized and antigen retrieved. After washing with phosphate buffered saline (PBS), the tissue sections were incubated with 3\% hydrogen peroxide and incubated with $2 \%$ bovine serum albumin. Then 1:50 goat polyclonal anti-Galectin-4 (Q-20) (sc-19289, Santa Cruz Biotechnology) or anti-Myosin-1a (C-12) (sc-32698, Santa Cruz Biotechnology) antibody was applied. After the antibody, N-Histofine High Stain HRP (MULTI) (Nichirei Biosciences, Tokyo, Japan) kit was used. The peroxidase activity was visualized by immersing tissue sections in N-Histofine DAB-2V (Nichirei Biosciences), resulting in a brown reaction product. Tissue sections were finally counterstained with hematoxylin and mounted.

\section{Immunohistochemical Evaluation and Data Analysis}

Cells with overexpressions of Galectin-4 and Myosin1a were examined and counted. Five fields/slide/rat were selected and documented under a light microscope with 400x magnification, then counted by two trained examiners. Counted cells were then statistically analyzed with SPSS Statistics, version 17.0 (SPSS Inc., Chicago, IL, USA). The $p$-value $<0.05$ was considered significant.

\section{Results}

There was no significant different for age and body weight among the three groups prior to intervention $(p>0.05)$. The rats induced by LPS showed slight inflammation 


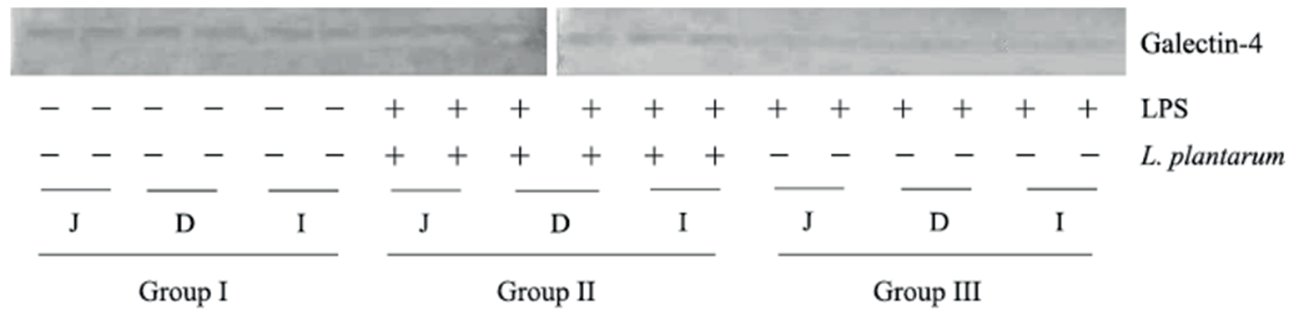

Figure 1. L. plantarum restored amount of Galectin-4 protein in duodenum, jejunum, and ileum of LPS-induced rats. Duodenum, jejunum, and ileum lysates of LPS-induced and/or L. plantarum-treated rats were subjected to western blot analysis to detect Galectin-4. J: jejunum, D: duodenum, I: ileum.

for 1-2 days. No adverse event was observed for administration of L. plantarum.

\section{L. plantarum Restored Amount of Galectin-4 Protein in} Duodenum, Jejunum, and Ileum of LPS-treated Rats Western blot results showed that Galection-4 was observed in all duodenum, jejunum, and ileum of Group I (Figure 1). However, Galection-4 protein was not clearly detected in Group II. LPS diminished Galection-4 protein in all duodenum, jejunum, and ileum. With the treatment of $L$. plantarum, Galection-4 protein was then clearly redetected as shown in Group III.

\section{L. plantarum Restored Number of Galectin- $4^{+}$Cells in} Duodenum, Jejunum, and Ileum of LPS-treated Rats

The highest number of Galectin- $4^{+}$cells was found in ileum, followed by jejunum, then duodenum (Figure 2). Numbers of Galectin- $4^{+}$cells were decreased significantly in the LPS-induced jejunum $(p=0.007)$, duodenum $(p=0.005)$ and ileum $(p=0.004)$ (Table 1). Under the treatment of $L$. plantarum, numbers of Galectin- $4^{+}$cells were then significantly restored.

\section{L. plantarum Restored Amount of Myosin-1a Protein in} Duodenum, Jejunum, and Ileum of LPS-treated Rats Myosin-1a was observed in all duodenum, jejunum, and ileum of Group I (Figure 3). However, Myosin-1a protein was not detected in Group II. LPS totally abolished Myosin-1a protein in all duodenum, jejunum, and ileum. With the treatment of $L$. plantarum, Myosin-1a protein was then clearly redetected as shown in Group III.

\section{L. plantarum Restored Number of Myosin-1 $\mathrm{a}^{+}$Cells in} Duodenum, Jejunum, and Ileum of LPS-treated Rats The highest number of Myosin- $1 \mathrm{a}^{+}$cells was found in duodenum (Figure 4). Numbers of Myosin- $1 \mathrm{a}^{+}$cells were decreased significantly in the LPS-induced jejunum $(p=0.007)$, duodenum $(p=0.001)$ and ileum $(p=0.008)$ (Table 1). Under the treatment of L. plantarum, numbers of Myosin- $1 \mathrm{a}^{+}$cells were then significantly restored.

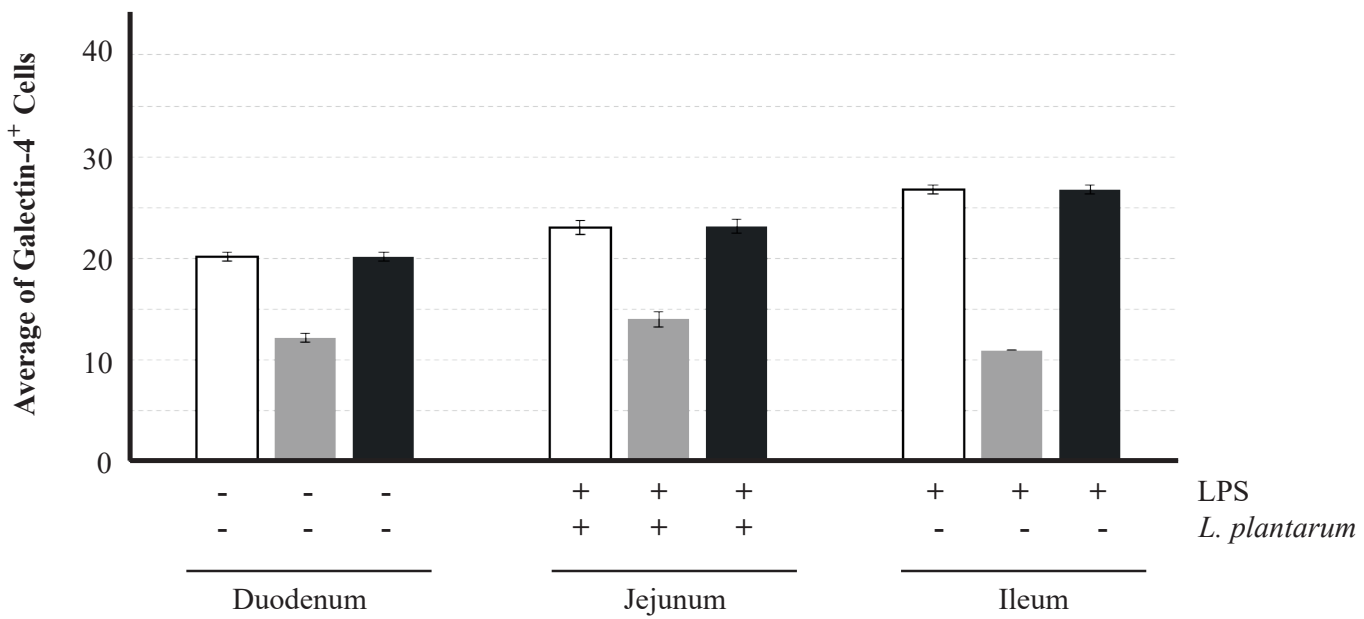

Figure 2. L. plantarum restored number of Galectin-4 ${ }^{+}$cells in duodenum, jejunum, and ileum of LPS-induced rats. Galectin-4immunohistochemically-overexpressed cells in duodenum, jejunum, and ileum of LPS-induced and/or L. plantarum-treated rats were examined and counted. 


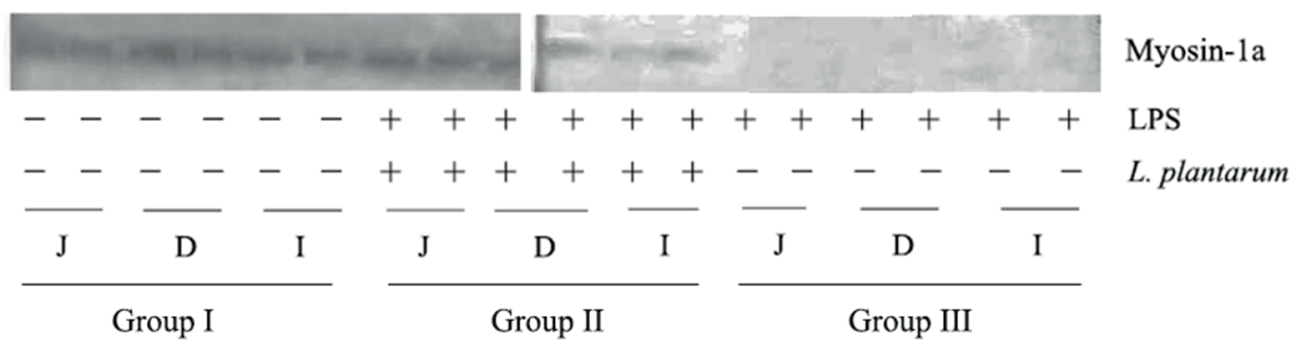

Figure 3. L. plantarum restored amount of Myosin-1a protein in duodenum, jejunum, and ileum of LPS-treated rats. Duodenum, jejunum, and ileum lysates of LPS-induced and/or L. plantarum-treated rats were subjected to western blot analysis to detect Myosin-1a. J: jejunum, D: duodenum, I: ileum.

\section{Discussion}

Galectin-4 is a protein that maintain integrity of intestinal membrane through stabilization of lipid raft and retain functionality of intestinal immune-regulation through selective T-cell apoptosis and cell cycle control.(1,8) Meanwhile, Myosin-1a is an important protein with its multifunctionality, and mainly maintain structure of villi core. $(2,9,10)$ In human, Myosin-1a is found mainly in intestine and smooth muscle, with considerable amount found in duodenum.(11) Healing mechanism of mucosal barrier will involve the process of regaining impermeability of tight junction with Galectin-4 and Myosin-1a as biomarkers of tight junction repair.

In this study, inflammation was induced by administrating LPS. L. plantarum IS-20506 probiotic significantly increased both Galectin-4 and Myosin-1a expressions in duodenum, jejunum, and ileum. It has been reported that probiotics may induce brush border repair through Mitogen-activated Protein Kinase (MAPK)/ Extracellular Signal-regulated Kinase (ERK) activation. MAPK/ERK has been well known to play important role in cell proliferation.(12) Peptidoglycan and teichoic acid exposure provided by probiotic may increase cells proliferation and promote the repair.(13)

Based on our findings, Galectin-4 is expressed more in ileum compared to duodenum and jejunum. L. plantarum IS-20506 probiotic relatively increased activity in more distal parts of LPS-induced intestine, as demonstrated by total Galectin-4 difference in each segment. This is in in line with the study of probiotic survivability using $L$. plantarum ST16Pa.(14) The study showed that, more activity of $L$. plantarum ST16Pa in the more distal part of intestine.(14) Hence, Galectin-4 may precede partial recovery rather than full recovery after administration of L. plantarum IS-20506. Myosin-1a exhibited contrasting behavior compared to Galectin-4. Although LPS-suppressed Myosin-1a was significantly restored by L. plantarum IS-20506 probiotic, the Myosin-1a expression was lower in distal part of

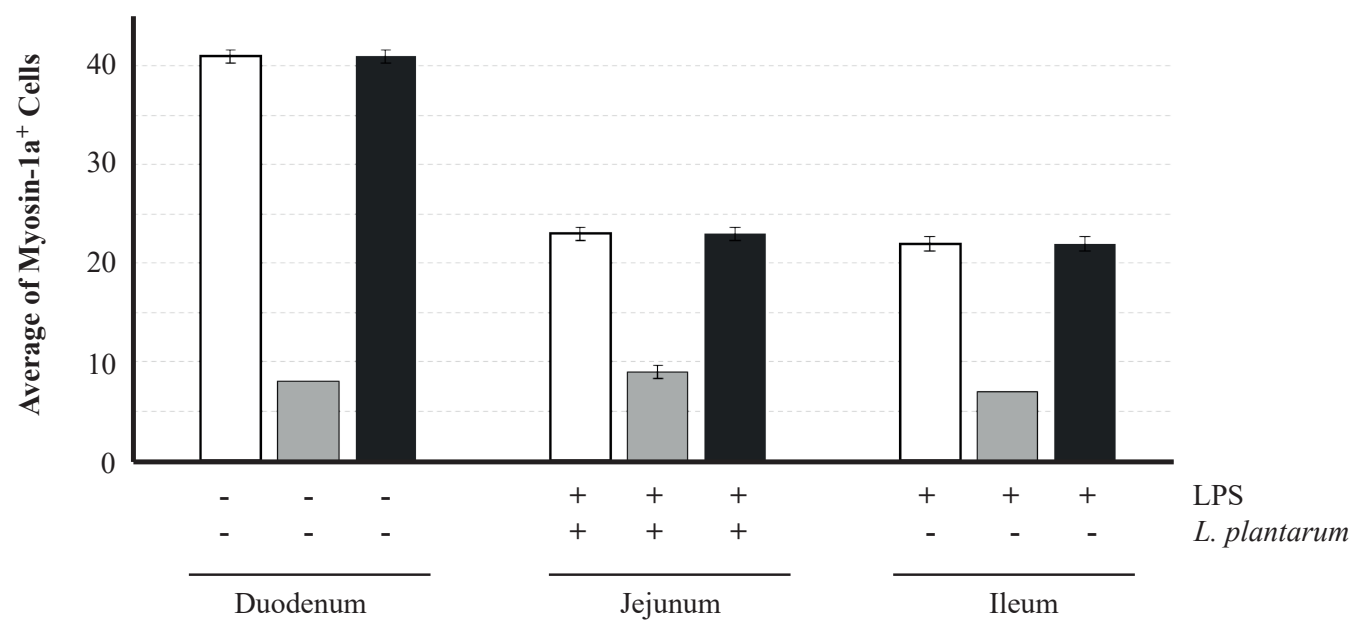

Figure 4. L. plantarum restored number of Myosin-1a ${ }^{+}$cells in duodenum, jejunum, and ileum of LPS-treated rats. Myosin-1aimmunohistochemically-overexpressed cells in duodenum, jejunum, and ileum of LPS-induced and/or L. plantarum-treated rats were examined and counted. 
Table 1. Statistical Differences of Galectin-4 and Myosin-1a between groups.

\begin{tabular}{cccccccc}
\hline \multirow{2}{*}{ Group } & \multicolumn{3}{c}{ Galectin-4* } & & \multicolumn{3}{c}{ Myosin-1a* } \\
\cline { 2 - 5 } \cline { 6 - 8 } & Duodenum & Jejunum & Ileum & & Duodenum & Jejunum & Ile um \\
\hline I vs. II & 0.005 & 0.007 & 0.004 & & 0.001 & 0.007 & 0.008 \\
I vs. III & 0.510 & 0.701 & 0.471 & & 0.531 & 0.571 & 0.570 \\
II $v$ s. III & 0.004 & 0.007 & 0.003 & & 0.001 & 0.005 & 0.005 \\
\hline
\end{tabular}

*Mann-Whitney test, significant if $p<0.05$. I: first group, treated with distilled water daily; II: second group, treated with LPS on the first day, then treated with distilled water daily; III: third group, treated with LPS on the first day, then treated with L. plantarum daily on the following days.

intestine. This pattern is still unknown or whether exclusive to Wistar rat. However, a protein mapping study showed that Myosin-1a is expressed slightly higher in duodenum compared to the rest of intestine.(11)

Administration of $L$. plantarum IS-20506 probiotic after LPS induction in rats tended to increase Myosin1a expression compared to the LPS-induced group. Our finding is line with the study of Lactobacillus casei probiotic in Giardia lamblia-infected Balb/c mice.(15) L. casei probiotic administration showed a significant increase of overall mass of intestine compared to control on both pre- and post-infection in brush border damaged due to giardiasis, malnutrition, and the combination of both; a finding that is supposed to be linear to the mass-creating nature of Myosin-1a.

\section{Conclusion}

L. plantarum IS-20506 probiotic may facilitate the repairment of damaged intestinal brush border as demonstrated by significant restoration of Galectin- 4 and Myosin-1a expressions in duodenum, jejunum, and ileum of LPS-induced rats. Further studies are still needed to investigate the extra-intestinal effects, safety, long-term effect, and overtime time dependent efficacy of L. plantarum IS-20506 probiotic.

\section{References}

1. Cao ZQ, Guo XL. The role of galectin-4 in physiology and diseases. Protein Cell. 2016; 7: 314-24.

2. Tyska MJ, Mackey AT, Huang JD, Copeland NG, Jenkins NA, Mooseker MS. Myosin-1a is critical for normal brush border structure and composition. Mol Biol Cell. 2005; 16: 2443-57.

3. Tash BR, Bewley MC, Russo M, Keil JM, Griffin KA, Sundstrom JM, et al. The occludin and ZO-1 complex, defined by small angle $\mathrm{X}$-ray scattering and NMR, has implications for modulating tight junction permeability. Proc Natl Acad Sci USA. 2012; 109: 10855-60.

4. Oshima T, Miwa H. Gastrointestinal mucosal barrier function and diseases. J Gastroenterol. 2016; 51: 768-78.

5. FAO/WHO. Probiotics in Food: Health and Nutritional Properties and Guidelines for Evaluation. Corboda: FAO/WHO; 2006.

6. Akuzawa R, Surono I. Fermented Milks. In: Roginski H, Fuquay J, Fox P, editors. Encyclopedia of Dairy Sciences. London: Elsevier; 2002. p.1045-9.

7. Athiyyah AF, Darma A, Ranuh R, Riawan W, Endaryanto A, Rantam FA, et al. Lactobacillus plantarum IS-10506 activates intestinal stem cells in a rodent model. Benef Microbes. 2018; 9: 755-60.

8. Paclik D, Danese S, Berndt U, Wiedenmann B, Dignass A, Sturm A. Galectin-4 controls intestinal inflammation by selective regulation of peripheral and mucosal $\mathrm{T}$ cell apoptosis and cell cycle. PLoS One. 2008; 3: e2629. doi: 10.1371/journal.pone.0002629.

9. Benesh AE, Nambiar R, McConnell RE, Mao S, Tabb DL, Tyska MJ. Differential localization and dynamics of class I myosins in the enterocyte microvillus. Mol Biol Cell. 2010; 21: 970-8.

10. McConnell RE, Tyska MJ. Leveraging the membrane - cytoskeleton interface with myosin-1. Trends Cell Biol. 2010; 20: 418-26.

11. Uhlén M, Fagerberg L, Hallström BM, Lindskog C, Oksvold P, Mardinoglu A, et al. Proteomics. Tissue-based map of the human proteome. Science. 2015; 347: 1260419. doi: 10.1126/ science. 1260419

12. Sandra F, Oktaviono YH, Widodo MA, Dirgantara Y, Chouw A, Sargowo D. Endothelial progenitor cells proliferated via MEKdependent p42 MAPK signaling pathway. Mol Cell Biochem. 2015; 400: 201-6.

13. Sashihara T, Sueki N, Ikegami S. An analysis of the effectiveness of heat-killed lactic acid bacteria in alleviating allergic diseases. J Dairy Sci. 2006; 89: 2846-55.

14. Todorov SD, Leblanc JG, Franco BD. Evaluation of the probiotic potential and effect of encapsulation on survival for Lactobacillus plantarum ST16Pa isolated from papaya. World J Microbiol Biotechnol. 2012; 28: 973-84.

15. Shukla G, Sidhu RK. Lactobacillus casei as a probiotic in malnourished Giardia lamblia-infected mice: a biochemical and histopathological study. Can J Microbiol. 2011; 57:127-35. 